\title{
The 2018 Muslim Pilgrimage to Mecca: Application of Grunig's Theory of Excellence Two-Way Communication Efforts to Avoid a Crisis
}

\author{
Saud A. Alsulaiman \\ Bowling Green State University \\ Bowling Green, OH USA \\ King Saud University \\ Riyadh, Kingdom of Saudi Arabia \\ Terry L. Rentner \\ Bowling Green State University \\ Bowling Green, OH USA
}

\begin{abstract}
Every year, millions of Muslims converge in the Kingdom of Saudi Arabia (KSA) to perform the Hajj pilgrimage. So how does a government prepare for a potential crisis when hosting an event of this magnitude? A content analysis guided this study on crisis communication strategies taken by the Saudi government before, during, and after Hajj 2018 and how Saudi Arabia utilized the media to deliver proactive messages to ensure a successful Hajj season. The study found that the government created and built a positive image in the media through the use of effective management, preemptive messages, and multiple communication channels.
\end{abstract}

Keywords - Crisis, Hajj, Kingdom of Saudi Arabia, Theory of Excellence, Two-Way Symmetrical Communication

SUGGESTED CITATION: Alsulaiman, S. A., \& Rentner, T. L. (2019). The 2018 Muslim pilgrimage to Mecca: Application of Grunig's theory of excellence two-way communication efforts to avoid a crisis. Proceedings of the International Crisis and Risk Communication Conference, Volume 2 (pp. 5-8). Orlando FL: Nicholson School of Communication and Media. https://doi.org/10.30658/icrec.2019.1

\section{INTRODUCTION}

Hajj, the six day Muslim pilgrimage to Mecca, is expected at least once in the lifetime of all Muslims who are physically and financially able to make this ritual journey. Every year, millions of Muslims head to the Kingdom of Saudi Arabia (KSA) during the last month in the Islamic calendar year to perform Hajj, the largest annual gathering of people in the world. The 2018 pilgrimage brought almost 2.4 million people to Mecca. Dealing with mass gatherings coming from all around the world with different cultures, languages, and backgrounds is a challenge for the government of Saudi Arabia. Safety of pilgrims, infrastructures readiness, coordination among ministries to provide all kinds of facilities (including transportation, housing, security, healthcare, sanitation, food), and other logistical supports are some of the unseen responsibilities to ensure a safe and pleasant experience for all pilgrims.

This kind of large gathering, however, does not come without potential risks, such as stampedes. For example, on Sept. 24, 2015 more than 700 pilgrims were killed and another 900 injured during Hajj [1]. Such incidents, plus intervention from some countries that try to politicize Hajj, challenge the Saudi government to craft a comprehensive plan that offers high 
quality services while at the same time address vulnerabilities and risks that may occur.

Grunig and Hunt's (1984) excellence theory served as the foundation for a content analysis to explore the effectiveness of the KSA's communication strategies during Hajj 2018 and how the government utilized the media, particularly social media, to deliver proactive messages before, during, and after this mega event.

\section{LITERAURE REVIEW}

The World Health Organizations (WHO) defines mass gatherings as the "concentration of people at a specific location for a specific purpose over a set of period of time, and which has the potential to cause strain on the local health system should a public health event occur" [2]. This is precisely the case during Hajj in which millions of people gather at a specific location and over some time, making this event more vulnerable to intentional crises, like terrorism and sabotage, or unintentional crises, such as disease outbreaks and natural disasters [3].

Despite cooperation among ministries, any Hajj season is vulnerable to all kinds of crises that could put pilgrims' lives in danger. In addition to the 2015 stampede, there was a fire in 1997 where over 340 pilgrims died and protests in 1987 that killed 400 pilgrims [1]. These tragedies increased the pressure on the Saudi government to find immediate and practical solutions for future Hajj. Solutions involved executing effective communication programs to deliver strategic messages to engage with stakeholders during this magnificent event. Stakeholders include all Saudi ministries and government entities, locals and residents in Saudi Arabia, foreign governments and private companies working with Saudis, Muslims, and pilgrims attending and observing Hajj event.

One of the crucial strategies scholars recommend before a crisis hits an organization is to build mutual relationships between an organization and its stakeholders [3]. Therefore, when a crisis strikes an organization, it could immediately reach out to its internal and external stakeholders [3]. Grunig and Hunt's Excellence Theory (1984) provided the theoretical foundation for this study. The theory posits that organizations dealing with a crisis often find themselves practicing the public information or two-way asymmetric models, but Grunig and Grunig (1992) found that practitioners would prefer practicing the two-way symmetric model "if they had the expertise to do so and if their organizations were receptive to the practice" [4, p.23]. Ideally, this means strategic planning for a crisis, known as crisis management and crisis communications.

The use of Grunig's two-way symmetrical communication model to emphasize and reinforce mutual relationships between an organization and its stakeholders is crucial for all types of organizations [5]. Through the use of strategic communication programs and activities, organizations could build robust and mutual relationships with stakeholders and be more effective [5]. Having dealt with major tragedies during past Hajj seasons should help the Saudis understand what future potential risks and types of crises could happen, highlighting the importance of strategic communication. In other words, the Saudi government must understand strategic communication as a central tool to manage this event, inform and educate stakeholders, and reduce risks.

\section{METHODS}

Researchers conducted a content analysis of 30 news articles written between July 20- September 01, 2018. This time frame coincided with the 2018 Hajj season that took place from August 20 - August 26, 2018. The researchers used the Google Internet search engine and entered the keyword phrase "Hajj in Saudi Arabia 2018" and randomly selected 30 news articles that appeared in newspapers such as the Arab News and Saudi Gazette newspapers. Researchers analyzed each article thoroughly to understand the type of messages and communication strategies used in articles written before, during, and after the 2018 Hajj season. The researchers then looked at the official Hajj 2018 Twitter account, @HajjMedia, and analyzed the content of tweets during the same period to determine the types of messages and communication strategies implemented during the 2018 Hajj season.

\section{RESULTS}

Analyses of both news articles and tweets revealed different communication strategies and best practices used during the 2018 Hajj season. These strategies aimed to reach and engage diverse audiences with different languages and from different ethnicities, races, and backgrounds. In other words, the strategies took into account the different cultures represented at Hajj and developed messages to communicate with these groups. A sample of communication strategies are discussed below.

\section{LEARNING FROM PREVIOUS CRISES}

Each Hajj season becomes an opportunity for the Saudis to learn and adjust services as needed. This includes learning from previous mistakes and crises that occurred in different Hajj seasons and at the same time being vigilant for any sign of risk or crisis that could disrupt the event. The Discourse of Renewal Theory emphasizes that a crisis provides organizations a learning opportunity to overcome and tackle issues and deficiencies [3]. Learning from previous failures and mistakes will lead to changes in procedures, approaches, and communication [3]. Implementation of new policies and innovations to prevent previous mistakes would not occur without the understanding of the importance of stakeholders' 
engagement in the process of enhancing and developing the Hajj journey for all pilgrims.

\section{TWO-WAY SYMMETRICAL COMMUNICATION}

The use of the two-way symmetrical communication model to engage with stakeholders during the 2018 Hajj season was explicitly manifested in communication programs and activities during Hajj. Examples of that were the Mecca Road Initiative [6], Hajj Hackathon [7], creation of a media center, use of e-bracelets to identify and track pilgrims [8], building a social media campaign theme, establishing a website that provides comprehensive information for pilgrims and journalists about Hajj, and integration of storytelling that contained videos and images to engage with stakeholders. Other examples shown by the official Twitter account of Hajj included integration of specific smartphone apps that helped pilgrims to easily mobilize and communicate with authorities at any time, an on-site survey to measure pilgrims' satisfaction and record their issues and concerns, creation of a command and control center, establishment of a Mecca operation center, the use of advanced DXC technology to help in managing the crowd [9], and implementation of an early health warning system [10]. For instance, a story about Malaysian pilgrims who participated in the cleanliness' campaign in Mecca and fought against littering had been circulated to many media outlets to show how Malaysian pilgrims made a great impression and served as a role model during Hajj. One post circulated among foreign governments and pilgrims praised the KSA for the services and hospitality during Hajj. Another post focused on the evaluation of 2018 Hajj activities and preparation for launching the 2019 Hajj plan.

Strategies specifically aimed to engage the media included The Kingdom Embraces the World portal. Once registered, journalists were given access to Hajj images, data from ministries and organizations, and contact information for questions.

\section{INTEGRATION OF SOCIAL MEDIA}

Besides utilizing different communication channels, like traditional media, billboards, digital screens, magazines, and brochures to communicate with stakeholders, the Saudis incorporated social media. Twitter, in particular, incorporated two-way communication to convey effective messages to inform, warn, raise awareness, and engage stakeholders and listen to their inquiries and/or concerns during Hajj. Analyses of tweets revealed consistent communication strategies implemented by the Saudis when using social media, including the use of different languages and the utilization of short videos, images, and stories that showed the dedication and efforts taken by stakeholders during Hajj. At the same time, hashtags, such as \#Onepeople and \#the Kingdom_Embraces the World, had been incorporated not only to engage with stakeholders but also to remind all pilgrims that the purpose of Hajj is the unification of people during a spiritual journey. These kinds of social media campaigns resulted in creating more than 17 billion impressions, according to the official Twitter account. Meanwhile, the campaign focused on telling various stories about pilgrims from different communities as well as Saudi workers and volunteers from different sectors who made significant impressions during Hajj. For instance, a short video showed 60 young Saudis who operated the Hajj Media Center engaging with internal stakeholders and showing appreciation for their efforts. Other examples highlighted people from various countries showing joyful moments and positive experiences via short videos.

These efforts could not be achieved without constant engagement with internal stakeholders, including all Saudi ministries and government entities, locals and residents, and external stakeholders such as foreign governments and private companies. All worked hand-in-hand to overcome challenges and hurdles to provide the best services and solutions for pilgrims. For instance, the Mecca Road Initiative between the Saudi government and some of the largest Muslim countries, like Indonesia and Malaysia, helped to facilitate easy travel and to fast track access to Saudi airports. The pre-clearance system gave pilgrims a fast track journey and allowed them to head directly to their accommodation without going through the customs in Saudi airports. This initiative was possible due to the cooperation between the Saudi government and stakeholders [9].

\section{DISSCUSSION}

This study provides crucial insights as to how effectively the Saudis managed the 2018 Hajj season through the implementation of best communication practices. On-going two-way communication often avoids a crisis, as demonstrated in how the Saudi Arabia government was able to build a positive image of Hajj. The study found that the government effectively practiced the two-way symmetric model by crafting effective messages, use of visual storytelling, and reliance on two-way communication before, during, and after the 2018 Hajj season. The government successfully created and built a positive image in the media through the use of effective management, preemptive messages, and multiple communication channels. Post-Hajj activities centered on appreciation and praising the success of Hajj from Saudi officials, governments from other countries, and celebrities. Communication messages included a review and evaluation of Hajj 2018, extremely important to stakeholders. Post-Hajj 2018 messages also focused on the preparation of Hajj 2019. For instance, for the first time during Hajj, the National Center for Performance Measurement (Adaa) interviewed pilgrims and asked them about services provided during Hajj. The survey aimed to measure pilgrims' satisfaction about simplicity of procedures, the readiness of infrastructure and location, and speed of services provided by staffs. Adaa has activated a system of measurement tools pointed toward better understanding pilgrims' satisfaction with government services provided during the Hajj season. This system of measurement was unveiled in line with the Kingdom's efforts to serve pilgrims and better 
facilitate governmental response to one of the world's largest annual pilgrimages. This kind of feedback, particularly listening to stakeholders' concerns and measuring their satisfactions enable the Saudi government to enhance and improve services for future Hajj seasons.

A mega event, like Hajj, with a massive and diverse audience, requires careful planning, robust research, and constant evaluation and assessment. Hosting such an event also requires collaboration with internal and external stakeholders to deliver and execute effective communication messages that resonate with the public and persuade them to act accordingly. It is the full reliance on the two-way symmetrical communication model that helped the Saudis to be effective in making the 2018 Hajj season successful [5]. The first crucial steps included a full understanding of stakeholders' needs and interests. Thus, an analysis of stakeholders is an indispensable step to take prior to releasing any information or communication activities. Once an organization determines its internal and external partners with whom to communicate, it could then develop what messages will effectively engage stakeholders as well as the when and where of releasing those messages.

\section{CONCLUSION}

The use of one-way communication has no place in today's crisis planning, especially given the surge in social media. The use of social media provided the Saudi government opportunities for two-way communication during Hajj 2018 and can be credited for much of it success. Social media offered immediate and greater public awareness as well as opportunities for stakeholders to participate and interact. These communication efforts may serve as models for other countries hosting large international events. Hosts of such mega events need to understand that the two-way symmetrical communication model is vital to engage stakeholders and to build mutual relationships. It is these mutual relationships that are considered the core foundation for every organization's crisis management plan. Without it, an organization cannot effectively manage a crisis.

\section{Author Biography}

Saud A. Alsulaiman, Ph.D. from Bowling Green State University. Bowling Green State University and King Saud University.

Terry L. Rentner, Ph.D. from Bowling Green State University. Bowling Green State University.

\section{REFERENCES}

[1] CNN (2018, September 16). Hajj pilgrimage fast fact. Retrieved from Internet Archive Website https://web.archive.org/web/20190507002120/https:/www.cnn.com/2013/06/21/world/hajj-fast-facts/index.html

[2] World Health Organization (WHO), (2018). Considerations for mass gathering events and Middle East respiratory syndrome coronavirus (MERS-CoV): Interim guidance. Retrieved from http://apps.who.int/iris/bitstream/handle/10665/272521/WHO-MERS-MG-15.1-Rev.1eng.pdf? sequence $=1 \&$ is Allowed $=\mathrm{y}$

[3] Ulmer, R. R., Sellnow, T. L., \& Seeger, M. W. (2017). Effective crisis communication: Moving from crisis to opportunity. Thousand Oaks, CA: Sage Publications Inc.

[4] Fearn-Banks, K. (2017). Crisis communications: A casebook approach ( $5^{\text {th }}$ ed). Mahwah, N.J: Lawrence Erlbaum Associates.

[5] Grunig, J., Grunig, L., \& Dozier, D. (2006). The Excellence Theory. In Botan, C. \& Hazelton, V. Public Relations Theory II (pp.171-198). Mahwah, NJ. Lawrence Erlbaum Associates, Inc.

[6] Saudi Gazette. (2018, July 17). Makkah road initiative launched in Indonesia. Retrieved from http://saudigazette.com.sa/article/539261/SAUDI-ARABIA/Makkah-Road-initiative-launched-in-Indonesia

[7] Al Arabiya. (2018, August 2). With 2,950 participants from 100 countries, Hajj Hackathon makes Guinness Record. Retrieved from http://english.alarabiya.net/en/features/2018/08/02/Saudi-Hajj-Hackathon-breaksGuinness-World-Record-in-participant-numbers.html

[8] BBC. (2016, June 30). Hajj pilgrims to be given e- bracelets. Retrieved from https://www.bbc.com/news/technology-36675180

[9] DXC.technology. (2019). Case studies: MRDA improves hajj safety and security. Retrieved from http://www.dxc.technology/Asia/case_studies/143291-mrda_improves_hajj_safety_and_security

[10] The World Health Organization (WHO). (2018). Early warning surveillance system implemented in Saudi Arabia for this year's hajj. Retrieved from http://www.emro.who.int/media/news/early-warning-surveillance-systemimplemented-in-saudi-arabia-for-this-years-hajj.html. 